Clinical practice

\title{
Fatal intoxication of a regular drug user following $N$-ethyl-hexedrone and ADB-FUBINACA consumption
}

\author{
Katalin Kovács ${ }^{\mathrm{a}}$, Éva Kereszty ${ }^{\mathrm{a}, *}$, Róbert Berkecz ${ }^{\mathrm{b}}$, László Tiszlavicz ${ }^{\mathrm{c}}$, Éva Sija ${ }^{\mathrm{a}}$, Tímea Körmöczi ${ }^{\mathrm{b}}$, \\ Nikolett Jenei ${ }^{\mathrm{d}}$, Hajnal Révész-Schmehl ${ }^{\mathrm{d}}$, László Institóris ${ }^{\mathrm{a}}$ \\ ${ }^{a}$ Department of Forensic Medicine, Faculty of Medicine, University of Szeged, Hungary \\ ${ }^{\mathrm{b}}$ Department of Medical Chemistry, Faculty of Medicine, University of Szeged, Hungary \\ ${ }^{\mathrm{c}}$ Department of Pathology, Faculty of Medicine, University of Szeged, Hungary \\ ${ }^{\mathrm{d}}$ Department of Forensic Toxicology, Hungarian Institute for Forensic Sciences, Hungary
}

\section{A R T I C L E I N F O}

\section{Keywords:}

$N$-Ethyl-hexedrone

ADB-FUBINACA

ADB-FUBINACA metabolites

Fatal outcome

Regular drug user

\begin{abstract}
A B S T R A C T
In Hungary, N-ethyl-hexedrone (NEH) was the most frequently seized stimulant designer drug in 2017, while among synthetic cannabinoids ADB-FUBINACA and AB-FUBINACA were the most popular. Symptoms of intoxication by these substances are well known but less is known about the pathology of overdose-related death.

$\mathrm{NEH}$-induced fatal intoxication has not been described in the literature and knowledge surrounding the particular circumstances of death could be useful better public education of risk and more adequate treatment of overdose patients. In this report, we characterize the case of a 23-year-old male regular drug user who died a few hours after NEH and ADB-FUBINACA consumption. His medical history showed arrhythmia in childhood, and some seizures. Autopsy found he had a BMI of 42.9, a hypertrophic and dilated heart, severe atherosclerosis of the valves, coronaries and the arteries, and edema of the internal organs. Histology confirmed those findings. Postmortem blood levels of $\mathrm{NEH}$ were $285 \mathrm{ng} / \mathrm{ml}$, along with $0.08 \mathrm{ng} / \mathrm{ml}$ ADB-FUBINACA and five ADB-FUBINACA metabolites. Based on the blood concentrations measured in suspected drug users ( $\leq 83.9 \mathrm{ng}$ / $\mathrm{ml}$ ) we hypothesize that NEH intoxication was the cause of death in this case, with heart disease being a co-factor and that the synthetic cannabinoid effect might have been accompaniment.

This case also offered the opportunity to identify the metabolites of ADB-FUBINACA in the blood. We identified metabolites in the post-mortem blood by comparing them to human liver microsomal enzyme metabolites in vitro. Three major and two minor metabolites were found in the blood, of which two could only be derived from ADB-FUBINACA, as opposed to other cannabinoids.

The case highlights the importance of the complex analysis of drug related deaths by medico-legal autopsy, histopathology and toxicology.
\end{abstract}

\section{Introduction}

Regular use of stimulant illicit and/or designer drugs can lead to serious adverse health effects (e.g. cardiomyopathy ${ }^{1,2}$, neurodegeneration $\left[{ }^{3},{ }^{4}\right]$, etc.) and increasing tolerance requiring higher doses, over time. Thus, the risk of adverse effects increases with prolonged drug abuse.

Identification of stimulant designer drugs (SDDs) is not possible purely based on clinical signs ${ }^{5}$, because (1) clinical symptoms overlap in multiple drug types, (2) frequent multi-drug use, (3) incorrect information about the abused substance provided by the intoxicated patients (e.g. the term "crystal" refers to several stimulants). In addition, no specific autopsy record is available in the literature for a given SDD. N-ethyl-hexedrone (NEH) is a relatively new cathinon, first confiscated in Hungary in February 2016. According to the Hungarian Institute for Forensic Sciences (HIFS), cathinones represented nearly $10 \%$ of seized material between September 2016 and August 2017, with an NEH ratio of $40-60 \%{ }^{6}$ We were unable to find objective and evidence-based dose-response information in the literature about NEH or its clinical symptoms. We only found one article, based on blog data of users' experience, which summarized its desired and undesired effects. According to these data, NEH doses range from $\sim 30 \mathrm{mg}$ to $\sim 150 \mathrm{mg}$, where $30-40 \mathrm{mg}$ is considered a low dose, typical doses are $50-60 \mathrm{mg}$, and higher doses are 70-90 mg, with very high doses in the 100-150 mg

\footnotetext{
*Corresponding author. Department of Forensic Medicine, Faculty of Medicine, University of Szeged, Kossuth L. sgt. 40, Szeged, H-6724, Hungary.

E-mail address: kereszty.eva.margit@med.u-szeged.hu (É. Kereszty).
} 
range (in some cases it can be as high as $250 \mathrm{mg}$ ). ${ }^{7}$ Our own assessment of user experience blog posts resulted in the similar conclusions. The most frequently described side-effects were hypertension, dehydration, lack of emotion, depression, paranoia, nausea, hangover, teeth grinding, jaw cramps, and nasal mucosa burning when snorted. ${ }^{7}$

Besides typical cannabis-like effects, ADB-FUBINACA has also undesired side-effects such as agitation, hypertension, tachycardia, or acute kidney injury. ${ }^{8}$ In Hungary in the period 2016-2017, 30-40\% of seized material was synthetic cannabinoids with an ADB-FUBINACA accounting for about $30-40 \%{ }^{6}$

There is little data in the literature on the metabolism of ADB-FUBINACA in the blood. This case allowed for the opportunity to characterize ADB-FUBINACA metabolites in the blood of the victim. In our fatal case sample we could identify five metabolites, four of which were also identified when ADB-FUBINACA was incubated with human liver microsomal enzymes in vitro.

In this study we present a case of fatal overdose involving NEH in a young male, who was a regular drug user. We considered data from the detailed medico-legal autopsy, histopathology and toxicology together with his medical history, so as to provide a thorough overview of the pathology of NEH overdose in this case. Our results on NEH overdose can be useful to evaluate the miscellaneous clinical data in the literature.

Such a complex evaluation of medical history, laboratory results and postmortem findings has not yet been described in the literature.

\section{Materials and methods}

\subsection{Chemicals}

The standards (ADB-FUBINACA of $99.0 \pm 2.2 \%$ purity and NEH $\mathrm{x}$ $\mathrm{HCl}$ of $99.4 \pm 3.5 \%$ purity) were kindly provided by the Drug Investigation Department of the Hungarian Institute for Forensic Sciences (HIFS). Their structure was confirmed by spectral data (IR, NMR and MS), and purity was determined by NMR. AB-FUBINACA-D4 (the internal standard (IS) for determination of ADB-FUBINACA) was purchased from Cayman Chemicals (Ann Arbor, MI, USA), MDPV-D8 (the internal standard for determination of NEH) from LGC (Germany). LC-MS grade solvents (distilled water, acetonitrile, ethyl-acetate) were purchased from VWR (Radnor, PA, USA). Formic acid (FA) and ammonia solution (35\%) of LC-MS grade were purchased from Fisher Scientific (Hampton, NH, USA). HLM (Cat. No. 452156) and the other reagents and solutions used in HLM experiments were purchased from Corning Gentest (Woburn, MA, USA). The other reagents were the products of Sigma-Aldrich, USA.

The blood sample for toxicological analysis was taken from the femoral vein and was analyzed for classical illicit and licit drugs, stimulant designer drugs ${ }^{9,10}$, and synthetic cannabinoids. Since January 2016, 18 new stimulant designer drugs and 27 synthetic cannabinoids are routinely measured (Table 1 ).

\subsection{Sample preparation and chromatographic conditions for determination of amphetamines and stimulant designer drugs}

For determination of amphetamines and stimulant designer drugs, $200 \mu \mathrm{l}$ blood sample was spiked with $10 \mu \mathrm{l}$ IS solution in methanol containing amphetamine-D5, metamphetamine-D5, MDMA-D5, MDEAD5, and MDPV-D8 ( $50 \mathrm{ng}$ of each), then $150 \mu \mathrm{l}$ buffer (the freshly prepared mixture of $8.5 \mathrm{ml}$ saturated $\mathrm{NaHCO}_{3}$ and $1.5 \mathrm{ml} 10 \mathrm{M} \mathrm{KOH}$ ), $300 \mu \mathrm{l}$ toluene and $0.3 \mathrm{~g}$ anhydrous sodium sulphate was added. The sample was vortex mixed for $15 \mathrm{~s}$ and centrifuged at $2500 \mathrm{rpm}$ for $8 \mathrm{~min}$ (K $26 \mathrm{D}$, Germany). $75 \mu \mathrm{l}$ of the toluene layer was transferred to $1.0 \mathrm{ml}$ GC vial containing $100 \mu \mathrm{l}$ insert (ViaLab, Germany), $5 \mu \mathrm{l}$ heptafluorobutiric-anhydrid (HFBA) was added and analyzed.

Analysis of amphetamines and stimulant designer drugs was performed by GC/MS (GC: Agilent 7820 A, MS: Agilent 7693, auto sampler
Table 1

New substances measured since 2016 January in the Toxicology Laboratory of the Szeged Forensic Department.

\begin{tabular}{|c|c|}
\hline Stimulants & Synthetic cannabinoids \\
\hline$N$-methylmephedrone & 5F-AMB \\
\hline $\begin{array}{l}\text { 4F-NPPP 1(4-fluorophenyl)-2-[(propan-2-yl) } \\
\text { amino]-pentan-1-on }\end{array}$ & 5F-AMBICA \\
\hline 4-methylbuphedrone & 5F-APP-PINACA \\
\hline$N$-ethyl-hexedrone & 5F-CUMYL-PEGACLONE \\
\hline \multicolumn{2}{|l|}{ 2-(ethylamino)-1-phenylhexan-1-one } \\
\hline 4-CEC 4-chloroethcathinone & $\begin{array}{l}\text { 5-fluoropentyl-3- } \\
\text { pyridinoylindole }\end{array}$ \\
\hline$\alpha$-PBP $\alpha$-pyrrolidinopentiothiophenone & 5F-MDMB-PICA \\
\hline$\alpha$-PBT $\alpha$-Pyrrolidinobutiophenone & 5F-MDMB-PINACA \\
\hline 4Cl-PPP 4'-chloro- $\alpha$-pyrrolidinopropio-phenone & 5F-MN18 \\
\hline 4F-PHP Pyrrolidinohexanophenone & AB-CHMINACA \\
\hline $\begin{array}{l}\text { Dipentylone 1-(1,3-benzodioxol-5-yl)-2- } \\
\text { (dimethylamino)pentan-1-one, bk-DMBDP }\end{array}$ & AB-FUBINACA \\
\hline $\begin{array}{l}N \text {-ethylpentylone } \beta \text {-keto- } \\
\quad \text { ethylbenzodioxolylpentanamine }\end{array}$ & AB-PINACA \\
\hline 4Cl-PVP 4'-chloro- $\alpha$-Pyrrolidinovalerophenone & ADAMANTYL-THPINACA \\
\hline M-PHP 4'-Methyl- $\alpha$-pyrrolidinohexiophenone & ADB-CHMINACA \\
\hline $\begin{array}{l}\alpha \text {-POP (PV9) 1-phenyl-2-(pyrrolidin-1-yl)octan- } \\
\text { 1-one }\end{array}$ & ADB-FUBINACA \\
\hline 3,4-CTMP 3,4-Dichloromethylphenidate & ADB-PINACA \\
\hline $\begin{array}{l}\text { MDPHP methylenedioxy- } \alpha \text {-pyrrolidino- } \\
\text { hexanophenone }\end{array}$ & AKB- $48 \mathrm{~F}$ \\
\hline $\begin{array}{l}\text { 3,4-dimethoxy- } \alpha \text {-PHP } \\
\text { 1-(3,4-dimethoxyphenyl)-2-(pyrrolidin-1- } \\
\text { yl)hexan-1-one }\end{array}$ & AMB-CHMICA \\
\hline \multirow{10}{*}{$\begin{array}{l}\text { TH-PVP 2-(pyrrolidin-1-yl)-1-(5,6,7,8- } \\
\quad \text { tetrahydronaphthalen-2-yl)pentan-1-one }\end{array}$} & AMB-FUBINACA \\
\hline & APP-CHMINACA \\
\hline & APP-FUBINACA \\
\hline & CUMYL-4CN-BINACA \\
\hline & CUMYL-PEGACLONE \\
\hline & FUB-AKB48F \\
\hline & MDMB-CHMICA \\
\hline & MDMB-FUBICA \\
\hline & MDMB-FUBINACA \\
\hline & THJ-2201 \\
\hline
\end{tabular}

76939, controlled by MSD Chemstation G 1701 DA software) in EI mode (EI, positive ions, $70 \mathrm{eV}$ ) using a DB-5MS ultrainert column $(25 \mathrm{~m} \times 0.25 \mathrm{~mm} \times 0.25 \mu \mathrm{m}, \mathrm{J} \& \mathrm{~W}$ Sci. Inc, USA), a single-taper liner with glass wool (Agilent, Cat. No. 5062-3587), and Helium 6.0 (Messer, Germany) as carrier gas at a constant flow rate of $1.9 \mathrm{ml} / \mathrm{min}$. The initial temperature of the oven was $100{ }^{\circ} \mathrm{C}$ with a hold time of $2 \mathrm{~min}$, which was then increased at $25^{\circ} \mathrm{C} / \mathrm{min}$ to $315^{\circ} \mathrm{C}$ and held constant for $4 \mathrm{~min} 2 \mu \mathrm{l}$ sample was injected in pulsed splitless mode (40 psi for $0.5 \mathrm{~min}$ ); the total run time was $14.6 \mathrm{~min}$. The temperature of inlet, transfer line, ion source, and quadrupole was adjusted to 250, 300, 230, and $150{ }^{\circ} \mathrm{C}$, respectively. The MS spectrum and peak location of the NEH-HFB derivative (Fig. 1) was determined in full scan (50-550 amu), while MS detection of the samples was performed in SIM (selected ion monitoring) mode. SIM ions, retention times and validation results are presented in Table 2. SIM chromatogram and mass spectrum of NEHHFB derivate detected in the sample is shown in Fig. 1.

\subsection{Preparation of blood samples for synthetic cannabinoid determination}

To $1 \mathrm{ml}$ blood sample $30 \mu \mathrm{l} 5 \%$ ammonia solution and $2 \mathrm{ml}$ ethyl acetate was added and mixed by vortex for $1 \mathrm{~min}$. $1.5 \mathrm{ml}$ of the upper layer was transferred to a clean test tube and evaporated to dryness by a Turbovap evaporator (Zymark, Hopkinton, MA, USA) at $50{ }^{\circ} \mathrm{C}$. The residue was dissolved in $200 \mu \mathrm{A}: \mathrm{B}=1: 1$ reagent (A: $0.1 \%$ formic acid in water, $\mathrm{B}: 0.1 \%$ formic acid in acetonitrile), and centrifuged (HeroLab, UniCen MR, Wiesloch, Germany) at $7900 \mathrm{rpm}$ for $10 \mathrm{~min}$ at room temperature. $20-\mu \mathrm{l}$ aliquots of supernatant were injected for LCMS/MS analysis. 

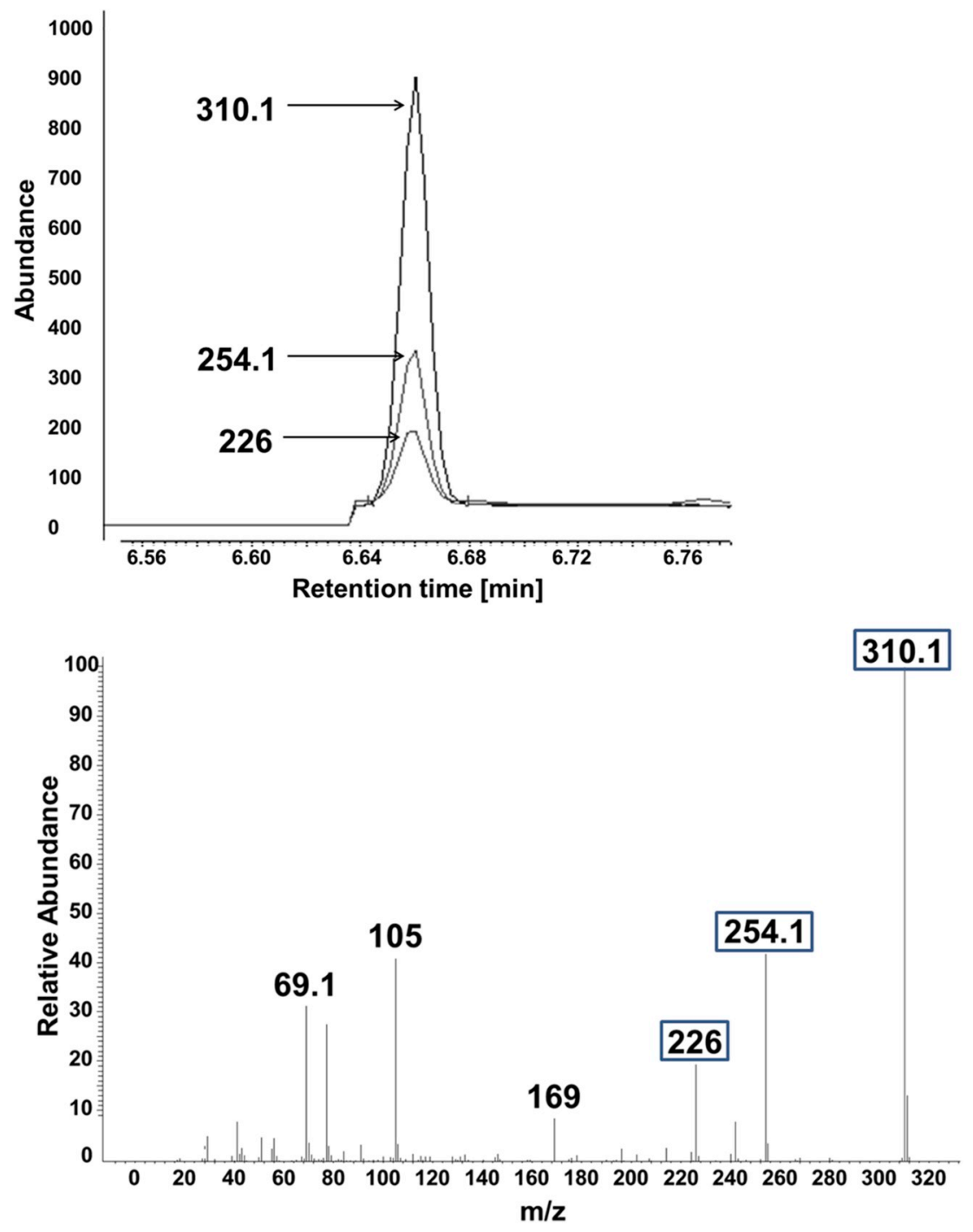

Fig. 1. SIM chromatogram and mass spectrum of N-ethyl-hexedrone-HFB in the blood sample.

\subsection{Incubation of ADB-FUBINACA with human liver microsomal enzymes} (HLM) and sample preparation

The incubation of ADB-FUBINACA with HLM was performed as described $^{11}$ with slight modification. The HLM reaction mixture consists $2.5 \mu \mathrm{L}$ pHLM, $2.5 \mu \mathrm{L}$ NADPH regenerating solution A, $0.5 \mu \mathrm{L}$ NADPH regenerating Solution B, $5.0 \mu \mathrm{L}$ superoxide dismutase (SOD), $10 \mu \mathrm{L}$ phosphate buffer $0.5 \mathrm{M}$, and $29 \mu \mathrm{L}$ deionized water and $0.5 \mu \mathrm{L}$ of a ADB-FUBINACA solution $(1 \mathrm{mg} / \mathrm{mL}$ in EtOH). After vortexing, HLM suspensions were incubated at $37^{\circ} \mathrm{C}$ for $30 \mathrm{~min}$. The reaction was quenched by $160 \mu \mathrm{l} 5 \%$ ammonia solution, $300 \mu$ l ethyl-acetate was added, vortexed thoroughly and centrifuged at room temperature at $2500 \mathrm{rpm}$ for $10 \mathrm{~min}$. $250 \mu \mathrm{l}$ supernatant was stored at $-80{ }^{\circ} \mathrm{C}$ until analysis. Before analysis, the sample was evaporated to dryness, and resolved in $100 \mu \mathrm{l}$ mobile phase (A/B, 1:1, v:v). For analysis $10 \mu \mathrm{l}$ was injected.

2.5. Liquid chromatography coupled to high-resolution mass spectrometry (LC-MS/MS) parameters for determination of ADB-FUBINACA and its metabolites

LC-MS/MS analysis was performed with a Q Exactive Plus hybrid quadrupole-Orbitrap mass spectrometer (Thermo Fisher Scientific, Waltham, MA, USA) coupled with a Waters Acquity I-Class UPLC ${ }^{\mathrm{Tm}}$
(Waters, Manchester, UK) apparatus. The LC system was controlled by MassLynx 4.1 SCN 901 (Waters, Milford, MA, USA). Data were acquired with Xcalibur 4.0 software (Thermo Fisher Scientific, Waltham, MA, USA).

A validated method was applied for determination of ADB-FUBINACA in the blood sample using a Kinetex C18 column $(100 \times 2.1 \mathrm{~mm}, 2.6 \mu \mathrm{m})$ combined with a guard column from Phenomenex (Torrance, CA, USA). Elution was achieved within $10 \mathrm{~min}$ with a mobile phase composed of $0.1 \%$ formic acid in water (A) and $0.1 \%$ formic acid in acetonitrile (B). Separation was performed using a Kinetex C18 column $(150 \times 2.1 \mathrm{~mm}, 2.6 \mu \mathrm{m})$ combined with a $50 \times 2.1 \mathrm{~mm}$ guard column from Phenomenex (Torrance, CA, USA). Elution was achieved within $45 \mathrm{~min}$ with a mobile phase composed of $0.1 \%$ formic acid in water (A) and $0.1 \%$ formic acid in acetonitrile (B) at a flow rate of $0.35 \mathrm{ml} / \mathrm{min}$. The gradient started with $10 \% \mathrm{~B}$ for $30 \mathrm{~min}$, ramped to $70 \% \mathrm{~B}$ at $30 \mathrm{~min}$, held for $1 \mathrm{~min}$, ramped to $100 \% \mathrm{~B}$ at $31 \mathrm{~min}$, held for $4 \mathrm{~min}$, and then returned to initial conditions within $1 \mathrm{~min}$.

Analysis of metabolites was performed using a Kinetex C18 column $(150 \times 2.1 \mathrm{~mm}, 2.6 \mu \mathrm{m})$ equipped with a guard column from Phenomenex (Torrance, CA, USA). Elution was achieved within $45 \mathrm{~min}$ with a mobile phase composed of $0.1 \%$ formic acid in water (A) and $0.1 \%$ formic acid in acetonitrile (B) at a flow rate of $0.35 \mathrm{ml} / \mathrm{min}$. The gradient program was the followings: $0 \mathrm{~min}-10 \% \mathrm{~B}, 30 \mathrm{~min}-70 \% \mathrm{~B}$, 
Table 2

Validation results.

Retetion time, SIM ions and linearity range of the substances

\begin{tabular}{|c|c|c|c|c|c|c|}
\hline \multirow{2}{*}{ Substance } & \multirow{2}{*}{$\mathbf{R t}$} & \multicolumn{3}{|c|}{ SIM ions } & \multirow{2}{*}{$\begin{array}{c}\text { Lin. Range } \\
\mathrm{ng} / \mathrm{ml}\end{array}$} & \multirow{2}{*}{$\mathbf{S} / \mathbf{N}^{*}$} \\
\hline & & $\mathbf{T}$ & Q1 & Q2 & & \\
\hline $\begin{array}{l}\text { N-ethyl- } \\
\text { hexedrone }\end{array}$ & 6.64 & 310 & $254(35 \%)$ & $226(18 \%)$ & $10-1500$ & 69 \\
\hline $\begin{array}{c}\text { ADB- } \\
\text { FUBINACA }\end{array}$ & 2.22 & 383.1877 & $\begin{array}{c}383.1877- \\
338.6632 \\
(19 \mathrm{eV})\end{array}$ & $\begin{array}{c}383.1877- \\
366.1612 \\
(10 \mathrm{eV})\end{array}$ & $0.01-10$ & 34 \\
\hline
\end{tabular}

*S/N (signal-to-noise ratio) was determined at the lowest concentration of the linearity range

The equations of the average calibration curves

NEH: $y=0.001791 x-0.034066$

ADB-FUBINACA: $\mathrm{y}=0.03722 \mathrm{x}+0.001836$

Intraday precision

\begin{tabular}{|c|c|c|c|c|}
\hline Substance & $\begin{array}{l}\text { Nominal cc } \\
(\mathrm{ng} / \mathrm{ml})\end{array}$ & RSD $\%$ & Bias \% & $\begin{array}{c}\mathbf{R}^{2} \text { of the } \\
\text { "average" } \\
\text { curve }\end{array}$ \\
\hline \multirow{8}{*}{$\begin{array}{l}\text { N-ethyl- } \\
\text { hexedrone }\end{array}$} & 10 & 11.3 & -12.2 & \multirow{8}{*}{0.9936} \\
\hline & 20 & 11.2 & -16.1 & \\
\hline & 50 & 6.45 & -9.50 & \\
\hline & 100 & 8.08 & -11.6 & \\
\hline & 250 & 9.85 & -4.73 & \\
\hline & 500 & 9.93 & -2.95 & \\
\hline & 1000 & 4.71 & 0.27 & \\
\hline & 1500 & 6.78 & 4.55 & \\
\hline \multirow{4}{*}{$\begin{array}{c}\text { ADB- } \\
\text { FUBINACA }\end{array}$} & 0.1 & 9.23 & 16.4 & \multirow{4}{*}{0.9972} \\
\hline & 1.5 & 3.98 & 0.96 & \\
\hline & 6 & 4.75 & 4.47 & \\
\hline & 10 & 4.27 & -1.63 & \\
\hline
\end{tabular}

Interday precision

\begin{tabular}{|c|c|c|c|}
\hline Substance & $\begin{array}{c}\text { Nominal cc } \\
(\mathrm{ng} / \mathrm{ml})\end{array}$ & RSD $\%$ & Bias $\%$ \\
\hline \multirow{3}{*}{$\begin{array}{l}\text { N-ethyl- } \\
\text { hexedrone }\end{array}$} & 20 & 9.82 & -3.25 \\
\hline & 250 & 7.58 & -2.27 \\
\hline & 1500 & 4.45 & 0.36 \\
\hline \multirow{3}{*}{$\begin{array}{c}\text { ADB- } \\
\text { FUBINACA }\end{array}$} & 0.1 & 3.60 & 15.9 \\
\hline & 1.5 & 1.86 & -2.03 \\
\hline & 6 & 4.69 & 1.96 \\
\hline
\end{tabular}


Table 2 (continued)

Selectivity
\begin{tabular}{|c|c|c|c|}
\hline Substance & Rt & SIM ions & $\begin{array}{c}\text { Matrix } \\
\text { avarage }\end{array}$ \\
\hline $\begin{array}{c}\text { N-ethyl- } \\
\text { hexedrone }\end{array}$ & \multirow{2}{*}{6.636} & 310 & no matrix* \\
\cline { 3 - 4 } & 254 & no matrix* \\
\cline { 3 - 4 } $\begin{array}{c}\text { ADB- } \\
\text { FUBINACA }\end{array}$ & 226 & no matrix* \\
\cline { 3 - 4 } & 2.22 & 383.1877 & no matrix* \\
\cline { 3 - 4 } & 338.6632 & no matrix* \\
\cline { 3 - 4 } & 366.1612 & no matrix* \\
\hline
\end{tabular}

no matrix*: interfering or overlapping matrix peak was not found

Recovery

\begin{tabular}{|c|c|}
\hline Substance & $\begin{array}{c}\text { Extraction } \\
\text { recovery }\end{array}$ \\
\hline $\begin{array}{c}\text { N-ethyl-hexedrone } \\
(250 \mathrm{ng} / \mathrm{ml})\end{array}$ & $83.0 \%$ \\
\hline $\begin{array}{c}\text { ADB-FUBINACA } \\
(1.5 \mathrm{ng} / \mathrm{ml})\end{array}$ & $98.9 \%$ \\
\hline
\end{tabular}

Stability

\begin{tabular}{|c|c|c|c|c|c|c|}
\hline \multirow{2}{*}{ Substance } & \multicolumn{7}{|c|}{ \% of the 0 hour's value } \\
\cline { 2 - 7 } & 4 & 8 & 12 & 16 & 20 & 24 \\
\hline $\begin{array}{c}\text { N-ethyl- } \\
\text { hexedrone } \\
(250 \mathrm{ng} / \mathrm{ml})\end{array}$ & 98.2 & 106 & 83.5 & 87.9 & 86.9 & 86.5 \\
\hline $\begin{array}{c}\text { ADB- } \\
\text { FUBINACA } \\
(1.5 \mathrm{ng} / \mathrm{ml})\end{array}$ & 93.2 & 93.2 & 90.8 & 92.8 & 89.6 & 90.1 \\
\hline
\end{tabular}

$31 \mathrm{~min}-100 \%$ B, $35 \mathrm{~min}-100 \%$ B, $36 \mathrm{~min}-10 \%$ B, and $45.0 \mathrm{~min}-10 \%$ B $(0.4 \mathrm{~mL} / \mathrm{min})$.

Autosampler and column oven temperatures were set to $4{ }^{\circ} \mathrm{C}$ and $50{ }^{\circ} \mathrm{C}$, respectively in both cases.

The blood samples and the in vitro metabolites of ADB-FUBINACA were analyzed in positive electrospray ionization (ESI) mode. The mass spectrometer was operated in full scan and parallel reaction monitoring acquisition (PRM) modes using a heated ESI source with the following conditions: capillary temperature $250^{\circ} \mathrm{C}$, S-Lens RF level 50, spray voltage $3.5 \mathrm{kV}$, sheath gas flow 50 , spare gas flow 2.5 and auxiliary gas flow 12.5. Mass range was set at $100-1000 \mathrm{~m} / z$ (full scan) with a resolution of 70000 (full scan) and 17500 (PRM). The automatic gain control (AGC) setting was defined as $3 \times 10^{6}$ (full scan) and $2 \times 10^{5}$ (PRM) charges and the maximum injection time was set to $20 \mathrm{~ms}$ (ADB-FUBINACA) and $100 \mathrm{~ms}$ (metabolites). Isolation window and the collision energy were set to $2 \mathrm{~m} / \mathrm{z}$ and $25 \mathrm{eV}$ (metabolites) in PRM mode. In case ADB-FUBINACA, the collision energy was optimized for quantifier $(19 \mathrm{eV})$ and qualifier ions $(18 \mathrm{eV})$.

Validation of the methods used for identification and quantitation of NEH and ADB-FUBINACA was performed as described. ${ }^{12}$ Extraction recovery of NEH was determined by adding $20 \mu \mathrm{l}$ standard solution in methanol (containing $250 \mathrm{ng} \mathrm{NEH}$ ) and $10 \mu \mathrm{l}$ IS to $200 \mu \mathrm{l}$ negative blood sample and processed as described. To indicate full recovery $20 \mu \mathrm{l}$ standard solution and $10 \mu \mathrm{l}$ IS was pipetted into an insert, evaporated to dryness under nitrogen, resolved in $75 \mu$ toluene by vortex mixing and $5 \mu \mathrm{l}$ HFBA was added. Five samples of both types were prepared and extraction recovery was calculated in percentages. For selectivity study eight negative blood samples were collected from the laboratory personals.

\subsection{Examination of the deceased}

A full-body autopsy was performed, following the Recommendation No3/1999 of the Council of Europe on the medico-legal autopsy.
Blood sample and tissue samples for histology were taken during autopsy. All samples were stained with hematoxylin and eosin. Sections of heart, liver, and pancreas were also stained by Crossmon's trichrom stain, lung and nasal mucosa by Prussian blue, and lung tissue immunochemistry was performed with CD3 antibody pan T lymphocyte marker.

\section{Case report}

\subsection{History}

According to his mother, her 23-year-old son used "crystal" together with his friends during the night and arrived home at 4.00 a.m. He felt sick and went to bed. When she went in his room, he was kneeling on his bed, then leaned forward, lost his consciousness and died at 9.30 a.m. When the ambulance arrived they attempted to resuscitate him, unsuccessfully. The general practitioner declared death and suspected intoxication. The police did not find illicit or designer drugs in his room.

Medical history included a heart murmur, identified at age 10 when his ECG showed sinus arrhythmia and central axis position. In 2013, he had general grand mal epileptic seizures. After the first seizure, he quickly regained consciousness. His neurological and internal medical examinations at that time were normal, and skull CT was negative. ECG showed tachycardia with a $98 / \mathrm{min}$ heart rate. The charts from that hospitalization indicate the patient was abdominally obese, smoked about 20 cigarettes per day, did not take any licit medication, and consumed alcohol occasionally. Five weeks later, the seizure recurred without any known triggering factor. Idiopathic generalized epilepsyrelated interictal signals were subsequently detected by EEG. He refused to cooperate and rejected medical treatment, in both cases. In 2015, he experienced two more seizures the morning after drinking alcohol at a New Year's party. Family history revealed his father had aortic surgery, and a cousin from his mother's lineage experienced adult epilepsy. 
Table 3

Autopsy and histological findings of the reported case.

\begin{tabular}{|c|c|c|c|}
\hline Organs & Weight (g) & Autopsy & Histology \\
\hline Brain & 1340 & $\begin{array}{l}\text { edema, hyperemic arachnoid mater, and a bilateral discreet softening } \\
\text { around the substantia nigra. }\end{array}$ & $\begin{array}{l}\text { severe congestion (hemosiderin laden macrophages) and edema, reactive } \\
\text { microgliosis. }\end{array}$ \\
\hline Lungs & right:780 & severe edema with diffuse subpleural petechia. & pulmonary edema, presence of hemosiderin-laden pulmonary \\
\hline & left: 620 & & $\begin{array}{l}\text { macrophages (chronic heart failure cells), megacariocytes of bone } \\
\text { marrow origin, lymphocytic interstitial pneumonitis (LIP). }\end{array}$ \\
\hline Heart & 600 & $\begin{array}{l}\text { dilated cardiomyopathy, hypertrophy, dilated mainly in the right side; } \\
\text { severe atherosclerosis on the valves and coronary arteries, especially on } \\
\text { the left anterior descending (LAD); blood distribution disorder in the } \\
\text { myocardium. }\end{array}$ & $\begin{array}{l}\text { perivascular connective tissue growth, extravascular presence of red } \\
\text { blood cells, myocardial hypertrophy and contraction bands necrosis. }\end{array}$ \\
\hline Liver & 4300 & enlarged and congested, fatty & $\begin{array}{l}\text { congestion, sinusoidal dilatation, early state of fibrosis, non-alcoholic } \\
\text { steatohepatitis (NASH), fatty degeneration. }\end{array}$ \\
\hline Spleen & 630 & enlarged and congested & decreasing white pulp and widening red pulp \\
\hline Kidneys & 500 & enlarged and congested & acute tubular necrosis \\
\hline Pancreas & & not specific & periductal fibrosis \\
\hline Nasal cavity & & edematous, hyperemic mucosa & $\begin{array}{l}\text { mucous membrane: nodular neural hyperplasia, chronic inflammation } \\
\text { and conjunction }\end{array}$ \\
\hline Arteries & & severe atherosclerosis in the main arteries & \\
\hline
\end{tabular}

In October 2015, he was involved in a traffic accident. No alcohol, illicit or designer drugs were found in his blood, but his urine contained $62.6 \mathrm{ng} / \mathrm{ml}$ pentedrone and $42.7 \mathrm{ng} / \mathrm{ml}$ alpha-PVP. His mother stated that the victim was a regular synthetic cannabinoid ('herbal') user.

\section{Results}

\subsection{Autopsy and histological findings}

Autopsy was performed 3 days after death and the autolysis of the body had already begun. The height of the corpse was $187 \mathrm{~cm}$ and weighed $150 \mathrm{~kg}$, having an extremely high BMI of 42.9. The face and neck regions were congested, and extensive post-mortem lividity appeared on the back. The conjunctive was hyperemic, the pupils were dilated, and some purple liquid was leaking from the nose. External examination showed no needle track marks or injury. Medico-legal autopsy found BMI 42.9, hypertrophic and dilated heart, severe atherosclerosis of the valves, coronaries and the arteries, and edema of the internal organs. Histology concluded the same. The results of autopsy and histological findings are summarized in Table 3. Considering the toxicology results (see below) we concluded, that the cause of death was likely the NEH intoxication, based acute heart and pulmonary failure. Chronic changes of vital organs and the other on-going diseases were likely co-factors of the fatal outcome.

\subsection{Toxicology}

For identification of NEH HFB-derivative in the blood sample, its retention time, the target and qualifier ions and their ratio were compared with the standard.

The validation results (Table 2) fulfilled the validation criteria for both substances. ${ }^{12}$ No interfering matrix peaks were detected in the selectivity studies that affected the performance of the methods. The lowest dose of NEH $(10 \mathrm{ng} / \mathrm{ml})$ provided a signal to noise $(\mathrm{S} / \mathrm{N})$ ratio of 69; the $\mathrm{S} / \mathrm{N}$ ratio was 34 for ADB-FUBINACA at the $0.01 \mathrm{ng} / \mathrm{ml}$ dose. These doses were regarded as the LOD and LOQ of the two substances. In the postmortem blood sample, $285 \mathrm{ng} / \mathrm{ml} \mathrm{NEH}$ and $0.08 \mathrm{ng} / \mathrm{ml}$ ADB-FUBINACA were determined by using external calibration method. The sample was negative for alcohol.

We also screened for synthetic cannabinoid metabolites in the blood samples. 3 major and 2 minor metabolites of ADB-FUBINACA were tentatively determined in the blood (Fig. 2) based on HLM experiments using the accurate $m / z$ values and the fragmentation behavior based on the literature. ${ }^{13-15}$ The rank of metabolites were calculated from the ratios of peak area of each metabolites and the total intensity of metabolites (Table 4).

\section{Discussion}

N-ethyl-hexedrone (NEH) lethal poisoning was the direct cause of death, as revealed by a detailed autopsy and toxicological blood sample analysis. Our report significantly adds to the knowledge base surrounding these substances as the currently available literature fails to provide information on the lethal dose or pathology of lethal overdose.

Stimulant designer drugs (SDDs) can affect multiple organs and cause acute and chronic symptoms such as hypertension, tachycardia, myocardial infarction, dysrhythmias, ventricular hypertrophy, hyperthermia, hyponatremia, acute kidney and liver failure, rhabdomyolysis, compartment syndrome, pulmonary edema and hypertension, cerebral stroke and hemorrhage, seizures, and psychosis. ${ }^{16,17}$

Severe edema of the brain can be the consequence of direct toxicity of illicit or designer drugs. Microglial activation can be induced by chronic SDD use, and is indicative of a long-standing progressive process $\left[{ }^{3},{ }^{4}\right]$, which may put a user at increasing risk of serious adverse events over time. The three epileptic seizures documented in the medical history were probably triggered by alcohol and/or drug use since no other reasons were registered.

Non-cardiogenic pulmonary edema and hemorrhage are frequently associated with drug toxicity. The acute and chronic hemorrhage (hemosiderin-laden macrophages) observed in this case could have been caused by toxic drug effects. Direct toxic effect on the capillary membrane of the alveoli or severe pulmonary edema can lead to acute emphysema, petechia, and hemorrhage, such as observed in this case. Stimulants are vasoconstrictors which could lead to anoxic capillary endothelial damage followed by reperfusion hemorrhage. ${ }^{18,19}$ The victim had dilated cardiomyopathy and this could also have contributed to the development of severe diffuse pulmonary edema and alveolar hemorrhage. Lymphatic interstitial pneumonitis (LIP) is a parenchymal response to chronic drug effects, but can also be induced by smoking.

SDDs exert their pharmacological effects via stimulation of catecholamine release and/or inhibition of reuptake. These can lead to myocardial infarction, aortic dissection, cardiomyopathy, and arterial damage, caused by intense vasoconstriction. They also predispose to arrhythmias, myocyte degeneration, hypertrophy, necrosis and fibrosis. While tachycardia and hypertension are associated with increased oxygen demand, vasoconstriction and vasospasm decrease cardiac oxygen supply. ${ }^{20}$ Beyond hypertension, the blogger self-reports don't mention symptoms in direct relation with these pathological changes. ${ }^{7}$

In the present case, severe dilated cardiomyopathy was found during autopsy. Although arrhythmia was diagnosed in childhood, the patient did not receive any medical treatment. The father's history of aortic surgery could indicate a hereditary factor predisposing to dilated cardiomyopathy, though no other records indicate that. Because of their 

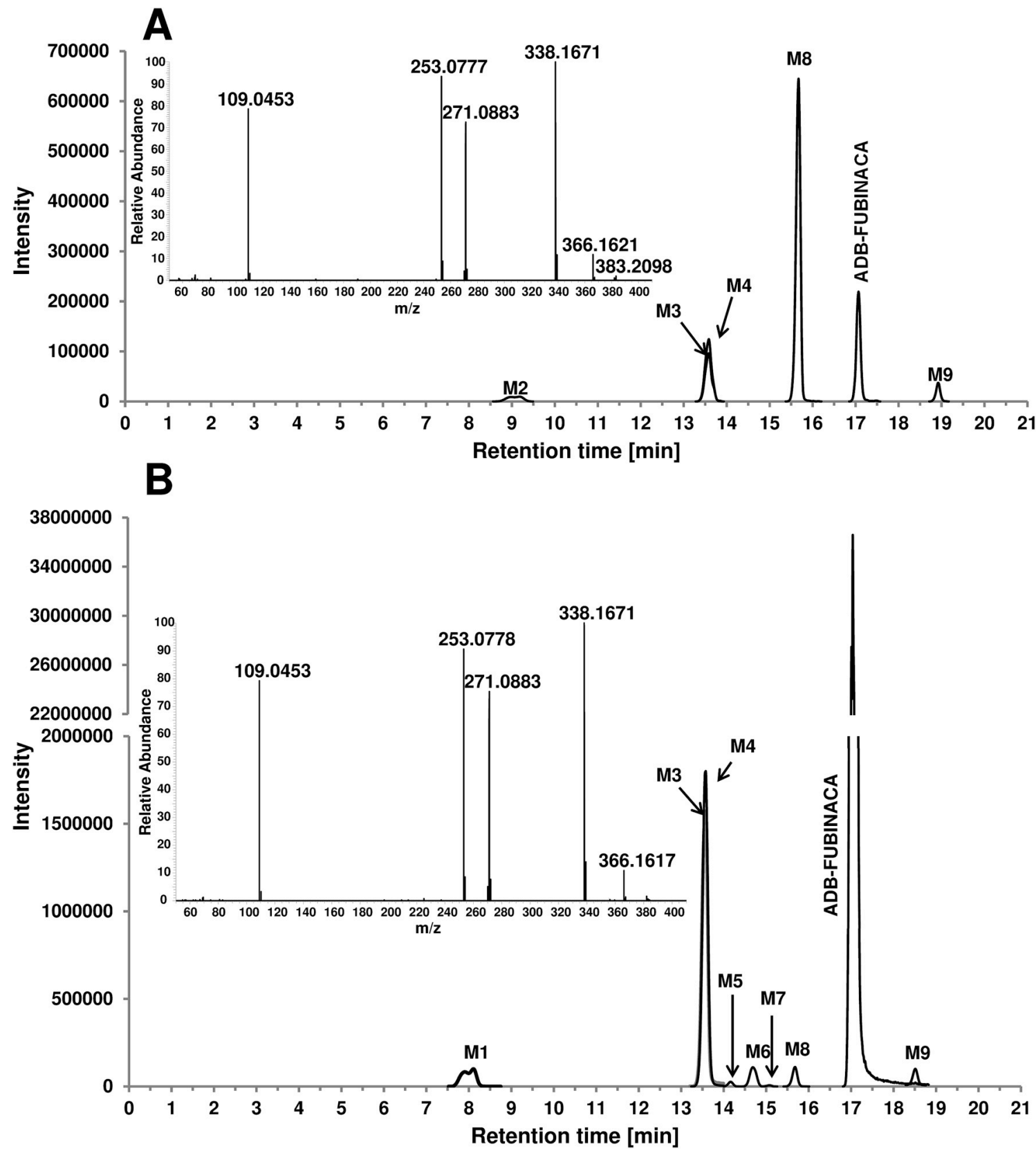

Fig. 2. Extracted ion chromatograms of ADB-FUBINACA and its metabolities in blood sample (A) and in HLM sample (B) with corresponding MS/MS specta of ADB-FUBINACA.

adverse effects - coronary vasospasm, persistent tachycardia and hypertension, and/or direct myocardial toxicity, the potent central and peripheral sympathomimetic effects as well as the increase in circulating catecholamine levels - the regular use of stimulants could lead to the development of dilated cardiomyopathy.

During autopsy contraction band necrosis and cardiomyocyte hypercontraction were also observed. These findings are common in SDDrelated deaths, as they are consequences of coronary vasoconstriction. ${ }^{21}$ Exhaustion of the white pulp in the spleen, the acute tubular necrosis, and megakaryocytes of bone marrow origin detected in the lung relate to a long-drawn circulatory deficiency before death. Atherosclerosis and coronary artery disease occurred at a significantly younger age in this patient than is characteristic for the general population.

Enlarged kidney and acute tubular necrosis - presented also in our case - following "bath salt" intoxication are described in the literature. SDDs elicit severe renal arterial vasospasm, producing renal hypoperfusion and ischemia, resulting in acute tubular necrosis. Furthermore, the direct toxic effect on tubular cells cannot be excluded either. ${ }^{22}$ Fatty changes of hepatocytes (NASH) and fibrosis can be the consequence of chronic stimulant use and/or obesity.

Hyperemia of the nasal mucosa relates to an acute effect, while nodular neuronal hyperplasia is probably the consequence of regular sniffing of stimulants.

More than $5 \mathrm{~h}$ (and probably less than 10-12 h) after consumption, the blood concentration of ADB-FUBINACA was only $0.08 \mathrm{ng} / \mathrm{ml}$, indicating a relatively short half-life. Screening for metabolites offers a longer detectability of synthetic cannabinoid use. In this study, five ADB-FUBINACA metabolites were identified in the blood of which 3 seem to be the main metabolites. Two of them (M2 and M4) originate only from ADB-FUBINACA, whereas, M3 and M9 are common metabolites of ADB-FUBINACA and MDMB-FUBINACA. ${ }^{13,14}$ Characterization of these metabolites may provide an opportunity for law 


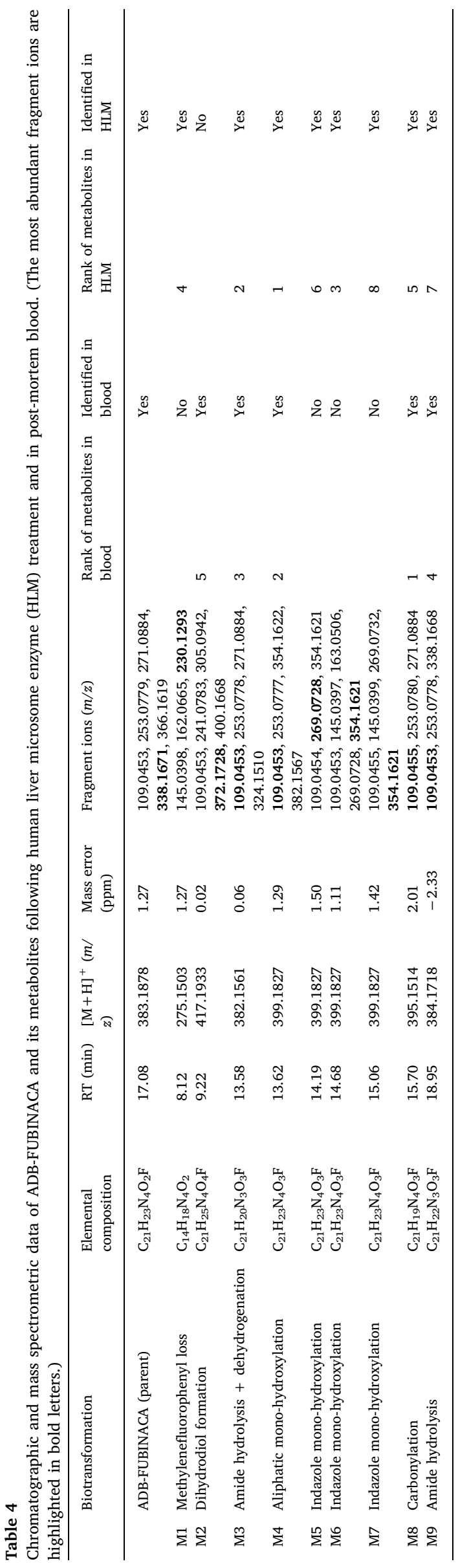

enforcement bodies to prove ADB-FUBINACA consumption at the later phase of elimination when the mother compound has already disappeared from the blood.

ADB-FUBINACA is known as a high-potency agonist of CB1 and CB2 receptors and was associated with several fatalities. A recent case report describes a 41-year-old woman who smoked "Mojo", became violent and aggressive, and shortly afterwards became unresponsive and died. In her postmortem blood, $1.1 \mathrm{ng} / \mathrm{ml} \mathrm{THC}, 4.7 \mathrm{ng} / \mathrm{ml} \mathrm{THC}-\mathrm{COOH}$, and $7.3 \mathrm{ng} / \mathrm{ml}$ ADB-FUBINACA were detected. On the basis of autopsy and toxicological analysis, the authors concluded that a combination of coronary disease, thrombotic occlusion, and synthetic cannabinoid use led to arrhythmia and death. The main autopsy findings of this ADB-FUBINACA-associated death were similar to those of stimulants. ${ }^{8}$ In another non-fatal case, a healthy 24-year-old man ingested two drops of e-cigarette fluid containing synthetic cannabinoids and was taken to the emergency department $30 \mathrm{~min}$ later. His symptoms were acute confusion, agitation, visual hallucinations, palpitations, tachycardia and increased blood pressure. In his serum sample (blood was taken at arrival), $5.6 \mathrm{ng} / \mathrm{ml}$ AB-FUBINACA and $15.6 \mathrm{ng} / \mathrm{ml}$ ADB-FUBINACA were identified. ${ }^{17}$

At the Department of Forensic Toxicology in Szeged, we examined the blood of a 20-year-old healthy man taken by the police and it contained $56.6 \mathrm{ng} / \mathrm{ml} \mathrm{NEH}$ and $12.1 \mathrm{ng} / \mathrm{ml}$ ADB-FUBINACA. He stated that he used synthetic cannabinoid about $2 \mathrm{~h}$ before sampling. At the time of sampling, his symptoms were increased blood pressure and heart rate $(147 / 71 \mathrm{mmHg}$ and $83 / \mathrm{min}$, respectively), hyperemic conjunctiva, and dilated pupils.

At the Department of Forensic Toxicology of HIFS, 1006 blood samples of living subjects were analyzed in 2017. Fourteen were positive for NEH. The concentration varied between 10.2 and $83.9 \mathrm{ng} / \mathrm{ml}$, with an average of $28.3 \mathrm{ng} / \mathrm{ml}$. Seven of these samples contained NEH alone $[10.2-37.8 \mathrm{ng} / \mathrm{ml}$.

In the present case, a much higher NEH concentration was measured together with $0.08 \mathrm{ng} / \mathrm{ml}$ ADB-FUBINACA. There is no information available whether the measured $285 \mathrm{ng} / \mathrm{ml} \mathrm{NEH}$ concentration is lethal or not, but ADB-FUBINACA at this low concentration was less likely to contribute to death. The route of administration for NEH is unknown but as needle track marks were not found, so it could have been oral or nasal. Oral administration is more probable as the victim died more than five hours after arriving home, and the relatively high NEH concentration can be attributed to a prolonged gastrointestinal absorption rather than to direct absorption through the nasal mucosa.

It is not known whether a $285 \mathrm{ng} / \mathrm{ml}$ blood concentration of $\mathrm{NEH}$ could be lethal for a healthy young man, but in the present case the unusually high NEH concentration together with deteriorated health conditions likely led to the fatal outcome.

\section{Conclusion}

This study gives new information on the toxic effects of NEH and ADB-FUBINACA combination in a fatal case. The detailed medico-legal autopsy with histopathological examination and the toxicological analysis of the blood sample were performed and reported in the Forensic Department of the University of Szeged, so we could give a complex evaluation of the cause of death, recognizing that fatal NEH poisoning had not been described before. High NEH concentration $(285 \mathrm{ng} / \mathrm{ml})$ was measured in the blood sample of a young man who died a few hours after consumption. This concentration is probably within the lethal range of NEH. We concluded that NEH poisoning was the direct cause of this unnatural death, while his health condition was very likely a co-factor in the fatal outcome. Detailed clinical data of cardiac history were not available, thus more comprehensive evaluation of the cardiac problems wasn't possible. We concluded this considering the lack of published laboratory data of survived overdose cases and our laboratory experiences. We think that the low concentration of ADB-FUBINACA $(0.08 \mathrm{ng} / \mathrm{ml})$ was below the toxic level at the time of 
death, so probably did not significantly contribute to death. The death certificate labeled it as an accompanying intoxication. We think that the NEH and ADB-FUBINACA blood-concentration could be even higher at the time of death as the result of their post-mortem decomposition. The presence of the mother compound gave an opportunity to identify its metabolites in the blood. Five metabolites were identified in the postmortem blood, two of which could be formed only from ADB-FUBINACA and not from other synthetic cannabinoids. The currently developed detection method of these metabolites could be used by law enforcement officials to confirm past ADB-FUBINACA consumption, when the mother compound has already disappeared from the blood and a urine sample is not available.

This case report underlines the importance of post-mortem toxicology, preferably together with autopsy and histology, in cases when the medical history does not explain an unexpected or sudden death.

\section{Acknowledgement}

This research was supported by the EU-funded Hungarian grant EFOP-3.6.1-16-2016-00008. The Ministry of Human Capacities, Hungary grant 20391-3/2018/FEKUSTRAT is acknowledged. The authors thank to the Drug Investigation Department of the Hungarian Institute for Forensic Sciences for providing chromatographic standards, and to Edit Kopasz and Gabriella Kovács for technical assistance.

\section{Appendix A. Supplementary data}

Supplementary data to this article can be found online at https:// doi.org/10.1016/j.jflm.2019.04.012.

\section{References}

1. Won S, Hong RA, Shohet RV, Seto TB, Parikh NI. Metamphetamine-associated cardiomyopathy. Clin Cardiol. 2013;36(12):737-742. https://doi.org/10.1002/clc. 22195.

2. Karch SB. The unique histology of metamphetamine cardiomyopathy: a case report. Forensic Sci Int. 2011;212:e1-e4. https://doi.org/10.1016/j.forsciint.2011.04.028.

3. Weis S, Bütter A. Neurotoxicology and drug-related disorders. Handb Clin Neurol. 2018;145:181-192 (Chapter 14). https://doi.org/10.1016/B978-0-12-802395-2. 00014-6.

4. Büttner A, Weis S. Neuropathological alterations in drug abusers. Forensic Sci Med Pathol. 2006;2(2):115-126. https://doi.org/10.1385/Forensic Sci. Med. Pathol. $: 2: 2: 115$.

5. Bahji A, Bajaj N. Historical, clinical, and public health consideration of 'bath salt' use: an emerging drug of abuse. Can J Addict. 2017;8(1):6-10.
6. Csesztregi T. Development of the Illicit Market. 2017; 2017 http://drogfokuszpont.hu/ wp-content/uploads/17 Csesztregi piac.pdf (in Hungarian).

7. Mikolajczyk A, Adamowicz P, Tokarczyk B, Sekula K, Gieron J, Wrzesien W, Stanaszek R. Determination of N-ethylhexedrone, a new cathinone derivative, in blood collected from drivers - analysis of three cases. Probl Forensic Sci. 2017;109:53-63.

8. Clark KG Shanks W, Behonock G. Death associated with the use of the synthetic cannabinoid ADB-FUBINACA. J Anal Toxicol. 2016;40:236-239https://doi.org/10 1093/JAT/bkv142.

9. Institóris L, Tóth AR, Molnár A, Árok Zs, Kereszty É, Varga T. The frequency of alcohol, illicit and licit drug consumption in the general driving population in SouthEast Hungary. Forensic Sci Int. 2013;224:37-43http://doi.org/10.1016/j. forsciint.2015.01.002.

10. Árok Zs, Csesztregi T, Sija É, et al. Changes in illicit, licit and stimulant designer drug use patterns in South-East Hungary between 2008 and 2015. Leg Med. 2017;28:37-44https://doi.org/10.1016/j.legalmed.2017.07.001.

11. Franz F, Angerer V, Moosmann B, Auwärter V. Phase I metabolism of the highly potent synthetic cannabinoid MDMB-CHMICA and detection in human urine samples. Drug Test Anal. 2017;9(5):744-753https://doi.org/10.1002/dta.2049.

12. Gunnar T, Ariniemi K, Lillsunde P. Validated toxicological determination of 30 drugs of abuse as optimized derivatives in oral fluid by long column fast gas chromatography/electron impact mass spectrometry. J Mass Spectrom. 2005;40:739-753. https://doi.org/10.1002/jms.846.

13. Carlier J, Diao X, Wohlfarth A, Scheidweiler K, Huestis MA. In vitro metabolite profiling of ADB-FUBINACA, a new synthetic cannabinoid. Curr Neuropharmacol. 2017;15(5):682-691https://doi.org/10.2174/1570159X15666161108123419.

14. Kavanagh P, Grigoryev A, Krupina N. Detection of metabolites of two synthetic cannabimimetics, MDMB-FUBINACA and ADB-FUBINACA, in authentic human urine specimens by accurate mass LC-MS: a comparison of intersecting metabolic patterns. Forensic Toxicol. 2017;35(2):284-300https://doi: 10.1007/s11419-017-0356-y.

15. Takayama T, Suzuki M, Todoroki K, et al. UPLC/ESI-MS/MS-based determination of metabolism of several new illicit drugs, ADB-FUBINACA, AB-FUBINACA, AB-PINACA, QUPIC, 5F-QUPIC and $\alpha$-PVT, by human liver microsome. Biomed Chromatogr. 2017;28(6):831-838https://doi.org/10.1002/bmc.3155.

16. Devlin RJ, Henry JA. Clinical review: major consequences of illicit drug consumption. Crit Care. 2008;12:202. https://doi.org/10.1186/cc6166.

17. Lam RPK, Tang MHY, Leung SC, Chong YK, Tsui MSHT, Mak WL. Supraventricular tachycardia and acute confusion following ingestion of e-cigarette fluid containing AB-FUBINACA and ADB-FUBINACA: a case report with quantitative analysis of serum drug concentrations. Clin Toxicol. 2017;55(7):662-667https://doi.org/10. 1080/15563650.2017.1307385.

18. Tomashefski JF, Felo JA. The pulmonary pathology of illicit drug and substance abuse. Curr Diagn Pathol. 2004;10:413-426. https://doi.org/10.1016/j.cdip.2004.04 009.

19. Bailey ME, Fraire AE, Greenberg SD, Barnard J, Cagle PT. Pulmonary histopathology in cocaine abusers. Hum Pathol. 1994;25:203-207.

20. Kay S, McKetin R, Duflou J, Darke S. Methamphetamine and cardiovascular pathology: a review of the evidence. Addiction. 2007;102:1204-1211. https://doi.org/ 10.1111/j.1360-0443.2007.01874.x.

21. Kuroda R, Nakajima M, Nagai H, et al. Small focal coagulation necrosis in the myocardium of a young methamphetamine user. Int $J$ Cardiol. 2013;164:e5-e6https://doi.org/10.1016/j.ijcard.2012.09.145.

22. Adebamino A, Perazella MA. Recurrent acute kidney injury following bath salts intoxications. Am J Kidney Dis. 2012;59(2):273-275. 